\title{
Materials for Incandescent Lighting: 110 Years for the Light Bulb
}

In 1879 Thomas Edison gave a gala exhibition that showed the world not just his electric light bulb but his complete electrical system for making it a practical, commercially viable way to illuminate entire cities. Edison's invention (and others at about the same time) of heating a thin filament to incandescence inside an evacuated glass bulb showed the first fundamental advance in lighting technology since direct flames.

In order for incandescent filaments to be put to use in light bulbs, suitable new materials had to be developed. The optimum material needed to be durable, inexpensive, and capable of being heated to incandescence over and over again.

In 1802 Sir Humphrey Davy discovered that he could use electricity to heat strips of platinum or other metals to incandescence, which would then give off light for some time. This proved impractical, though, because no satisfactory source of electricity was available to power the system, and also because the incandescent metal strands in air rapidly burned away. Seven years later, in 1809, Davy used a 2,000-cell battery to pass current through two charcoal sticks separated by four inches. The electricity arced across the gap, creating the first arc lamp.

By 1820 De la Rue had made the first attempt at an actual incandescent lamp, enclosing a platinum coil inside a section of glass tubing under a vacuum. In $1840 \mathrm{Sir}$ William Robert Grove lit an English auditorium with similar electric lamps-platinum coils heated to incandescence and covered by inverted glass tumblers in dishes partly filled with water. This light was feeble and impractical, but the cost of the current consumed in this one instance came to several hundred pounds per kilowatt-hour!

A year later the very first patent for an incandescent lamp went to Frederick de Moleyns in England. His lamp differed from those used by De la Rue and Grove, though, in that powdered charcoal bridged the gap between two platinum filaments inside an evacuated glass globe. A current passing through the platinum filaments heated the charcoal powder to incandescence. Unfortunately, the inside of the globe blackened quickly from the powdered carbon, and the lamp didn't last long.
In 1850 Edward G. Shepard invented a lamp that used only incandescent charcoal, and about the same time English physicist Sir Joseph Wilson Swan created carbon filaments out of paper. In $1856 \mathrm{C}$. de Chagny, a French inventor, patented an unusual lamp for mining which functioned with an incandescent platinum filament.

Using a V-shaped piece of graphite for his filament, Russian physicist Alexandre de Lodyguine in 1872 created a light source inside a sealed glass globe filled with nitrogen. Two hundred of de Lodyguine's bulbs were installed at the Admiralty dock in St. Petersburg, but maintenance costs and the bulbs' unreliability made the system impractical. In the same year the Russian S.A. Kosloff used multiple rods of graphite, also in a nitrogen-filled chamber, but this, too, yielded poor results.

By 1878 Sir Joseph Wilson Swan, who 28 years earlier had created carbon filaments out of paper, gave a large-scale exhibition of public lighting with bulbs containing a filament of cotton thread treated with sulfuric acid and mounted in an evacuated glass bulb. Swan called his invention the "electric glow lamp."

Swan worked concurrently with Thomas A. Edison, and much controversy ensued over who deserved the credit for inventing the modern light bulb. Edison had begun working on the problem in 1877 and reportedly conducted over 1,200 experiments over the next two years. On October 21, 1879, Edison succeeded in lighting a bulb that used a carbonized sewing thread filament in an evacuated glass globe. The carbon filament was strung across the inside of the glass globe and brought out through sealed holes in the sides, where the ends of the thread were attached to an electric supply. His lamp burned steadily for two days, producing 1.4 lumens per watt, or about the light equivalent of 16 candles. (A modern $60 \mathrm{~W}$ tungsten-filament bulb produces $13.9 \mathrm{lu}$ mens per watt.)

With further experiments Edison found that with filaments of carbonized Bristol board ("visiting card paper") he could make a lamp burn for several hundred hours. Edison also began to use filaments made of carbonized bamboo. Swan, mean- while, introduced extruded cellulose filaments for light bulbs in 1883 , but by then Edison had made his name.

At his laboratory in Menlo Park, New Jersey, Edison gave the first public demonstration of his lighting system on December 21,1879 . The steamship "Columbia" became the first commercial installation to use Edison's light bulb in May 1880, installing 115 bulbs in a system that would operate successfully for 15 years. In 1881 a New York City factory used Edison's lighting system, and in the next two years more than 150 other places installed the new lighting, including the Savoy Theatre in London, which had been built for the Gilbert and Sullivan operas. Most urban areas, however, still used gas lighting facilities which had been installed decades before.

In 1886 Austrian chemist Karl Auer von Welsbach studied materials to find a way to create incandescent lighting with a gas burner. Welsbach developed a stiff spherical or cylindrical "mantle" of woven threads that glowed brilliantly when heated by the Bunsen gas burner in standard use. Originally, the threads were made of sea-island and Egyptian cotton soaked in a solution of $99 \%$ and $1 \%$ salts of thorium and cerium, respectively. Later, he replaced them with a skeleton of thorium oxide threads. The mantles were treated to make them strong enough to withstand transport and commercial sale. After the mantle had been lit on a gas burner though, the stabilizing material burned off and left a fragile web that could easily be damaged or destroyed by any shock. The incandescent mantle cast a garish greenish-white glow (characteristic of the gaslight era) because of the thorium/ cerium salts. The Welsbach gas mantle became the main source of city lighting until it was superseded by electric lighting; it remained a standard for rural lighting up until 1930.

Eventually, continued improvements in filament materials made the electric incandescent bulb a more practical option than even the Welsbach gas mantle. Also crucial to the functioning and long life of the light bulb was the attainment of a good vacuum inside the glass, which kept the filament material from oxidizing. Even small improvements in filament materials allowed a 
bulb either to be operated at a higher temperature (thereby producing brighter, whiter light) or to have a longer lifetime.

In 1905 Willis R. Whitney introduced the "metallized carbon filament," a thread heated to a very high temperature in an electric furnace before being installed in a bulb. Intense heating changed the carbon and gave it electrical properties more like that of a metal. The metallized carbon filament increased the output from Edison's 1.4 lumens per watt to about 4 lumens per watt.

The most important advance in filaments, though, was the search for materials other than carbon, culminating in the introduction of metallic filaments. Welsbach himself developed an electric lamp using a filament of incandescent osmium metal. Osmium-filament lamps were used from about 1899 to 1907 , but osmium itself was so rare that the filament material was prohibitively expensive.

In 1901, the German W.H. Nernst patented the "Nernst glower," an electrically heated filament made of rare-earth oxides (a standard commercial formula was $85 \%$ zirconium oxide and $15 \%$ yttrium oxide). In 1902, Russian chemist Werner von Bolton invented the tantalum-filament lamp, which produced 5 lumens per watt. The tantalum-filament lamp was introduced in the United States in 1906, but was replaced a year later by a pressed-tungsten filament yielding 8 lumens per watt.

Tungsten was found to be the ideal material for filaments: very robust, it had the highest melting point $\left(3370^{\circ} \mathrm{C}\right.$ or $\left.6098^{\circ} \mathrm{F}\right)$ of all metals that could be drawn into filament wires, and thus could run at a higher temperature to generate a whiter light.

However, researchers could not yet draw the very hard tungsten into a wire. They got around this by mixing powdered tungsten with a binder and then forcing the compound through a die. Under high temperatures, the binder burned away and the tungsten particles fused together, leaving an extremely fragile filament. William D. Coolidge found a way in 1910 to produce ductile tungsten, which could then yield strong tungsten filaments that could operate at a higher temperature than any previous filament material.

Tungsten, a readily available element, has characteristics so ideal for use in light bulbs that it is doubtful a superior material will be found. One pound of tungsten metal can produce enough filaments for $75,00040 \mathrm{~W}$ light bulbs.

Like early carbon-filament lamps, tungsten light bulbs experienced migration of the filament material to the inside of the glass bulb. This led to a blackening of the

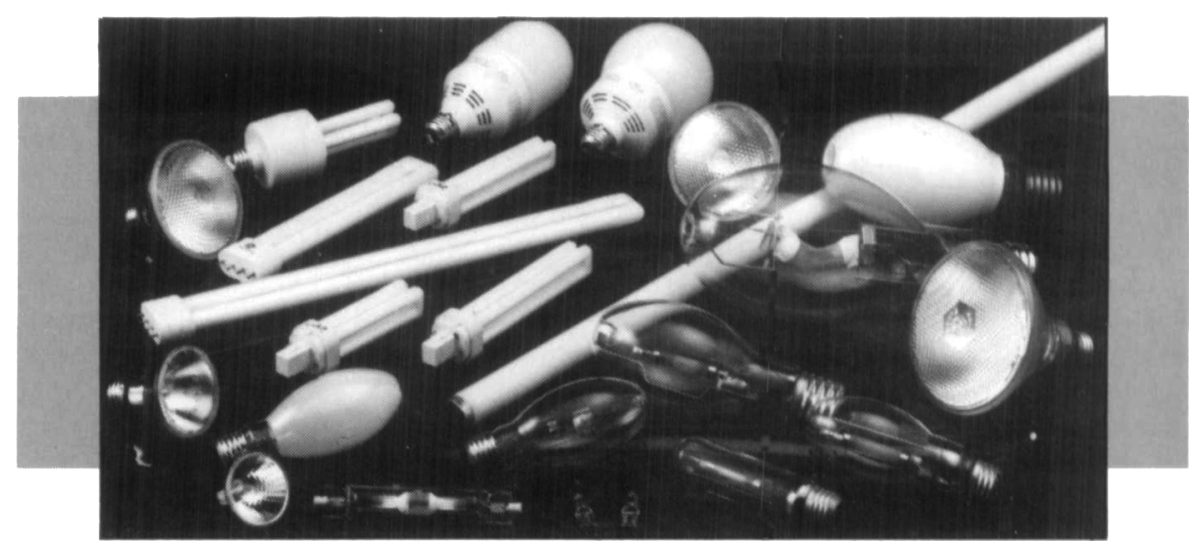

Today's newest lamps use modern engineered materials for lamp envelopes, phosphors, optical coatings, and containers for high-temperature gas discharges. Shown are compact halogen incandescent lamps, biaxial and linear fluorescent lamps with good tri-phosphor coatings, and new low-wattage metal-halide and high-pressure sodium high-intensity discharge lamps. The new 60-watt Halogen-IR ${ }^{T M}$ lamp has the life and performance features of a 150-watt conventional lamp thanks to optical coatings that trap infrared emissions from the filament inside a quartz filament tube. This lamp represents a $40 \%$ improvement in lamp efficiency over conventional incandescent lamps. (Photo courtesy of GE Lighting.)

bulb and lower light output in addition to a thinning of the filament itself until it broke. Introducing inert argon gas into the bulb reduced this migration and also allowed the filament to be heated to an even higher temperature.

The tungsten filament was further improved by the creation of a coiled version, then the coiled-coil filament in 1937, which further increased the effective size of the filament. A tightly coiled filament reduced convection losses, especially in large lamps and allowed an additional $10-15 \%$ increase in efficiency.

These advances left manufacturers with the options of creating either a light bulb with an effectively infinite lifetime and low light output or a bright, efficient bulb that didn't last as long. Among themselves, manufacturers decided on a standard lifetime of 1,000 hours, with a color somewhat yellower than natural sunlight but still more acceptable than the oil lamp or the candle. This standard has been little modified since its original conception.

Recent developments in filament materials have produced the tungsten-halogen filament, introduced in 1959 and now widely used in automobile headlights. When operated at a temperature high enough for the greatest luminous efficiency, tungsten filaments evaporate rapidly and blacken the inside of a bulb. A small amount of iodine or other halogen enclosed in the bulb with the tungsten, however, engenders a "regenerative cycle" that rebuilds the filament as it evaporates. Evaporated tungsten migrates toward the bulb wall, where it reacts with the halogen. The tungsten halide then migrates back toward the incandescent filament, where it dissociates, depositing the tungsten back onto the filament and leaving the halogen free to repeat the cycle. Iodine is most commonly used in these types of bulbs because the temperatures needed to maintain the regenerative cycle fit well with other light bulb designs, and iodine is the least difficult of the halogens to process and handle. Because the halogens react with ordinary glass, the filament/halogen combination must be encased in a quartz bulb, which is much more expensive initially.

Ribbon filament lamps made with a strif of tungsten between 0.7 and $4 \mathrm{~mm}$ wide and up to $50 \mathrm{~mm}$ long have a low amper age and are used in microscopes, oscillo scopes, and recorders; higher amperag ribbon-filament lamps are used for pyro meter calibration and in spectrographi work.

Other advances have increased our knowledge about lighting and filament materials enough that lamps can be tailored to meet nearly every need. Lamps of enormous sizes have been made for lighthouses, searchlights, and floodlights, using not only incandescent filaments, but also arc discharges or fluorescent vapor. Microscopic lamps, down to thin optical fibers made of plastics, have been made for use in surgery. Few branches of materials research have had such rapid success or become such a part of modern life. Electric light is perhaps on par with running water as one of the essentials of "civilization."

KEVIN J. ANDERSON 


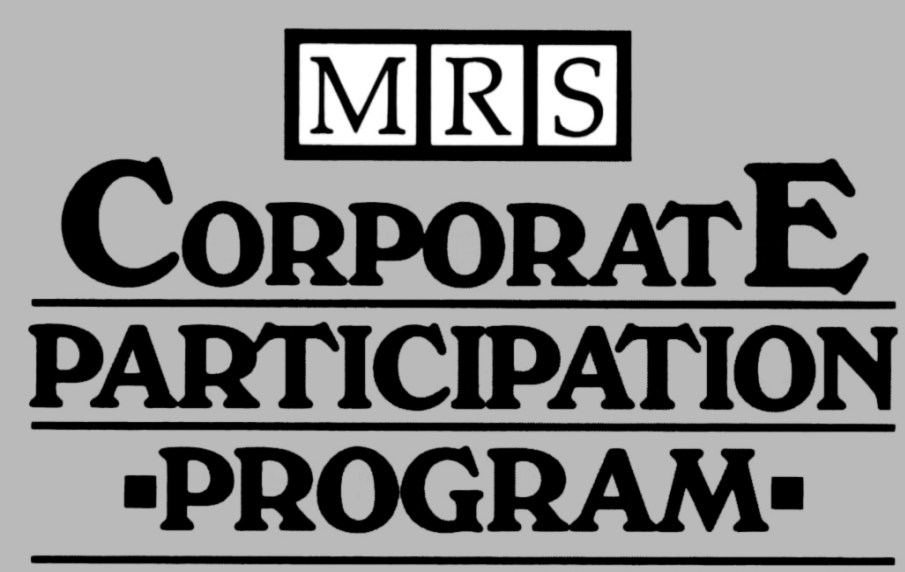

Organizations interested in influencing the growth and direction of interdisciplinary, basic research in materials are invited to take part in the MRS Corporate Participation Program as Corporate Affiliates. The program links the efforts of two key groups towards advancing development of materials of technological importance-organizations responsible for pioneering development and application of advanced materials and the Materials Research Society, which provides an interdisciplinary forum for the exchange of technical information among materials scientists in industry, government, and academia.

Corporate Affiliates assist the Society through their financial contributions in several ways. Primarily these contributions are used to fund programs for students, such as graduate student awards, travel grants for members of university chapters, short course scholarships, and the Distinguished Lecturer series. In addition, directed contributions frequently help MRS to produce symposia which are thorough interdisciplinary exchanges in new topical areas by providing the seed funding necessary to assist the attendance of key research workers. The nurturing of both student materials and effective programming of new topics is absolutely crucial to the Society. Each Corporate Affiliate is kept abreast of MRS activities in these and other ventures through a corporate representative and copies of the MRS Bulletin.

MRS Corporate Affiliates play a vital role in the Society by ensuring that the Society's technical programs are responsive to the interests of the research community and by broadening the financial base of the Society. MRS is the only scientific association devoted to promoting research on materials from a multidisciplinary perspective. The Society's rapid growth since 1973 is due to its unique method of matching the needs of industrial research organizations and to its quick response to changing interests in the materials science community.

\section{MAS Corporate Affiliate Benefits}

- A subscription to the MRS BULLETIN, the Society's monthly news publication.

- Recognition of support in all promotional material for MRS Fall and Spring Meetings.

- Advance notification of meeting programs and events.

- Advance consultation on topical program contents.

- Opportunity to purchase symposium proceedings at member prices.

- Opportunity to display corporate literature free of charge at MRS meetings.

- Opportunity to participate in job placement services free of charge at MRS meetings.

- Reduced booth rental rates at MRS equipment exhibits.

- Discounts on advertising in the MRS BULLETIN.

For further information about the MRS Corporate Participation Program, contact:

Kenneth E. Voss, Chair, Corporate Participation Committee, Engelhard Corporation, Menlo Park, CN28, Edison, New Jersey 08818; telephone (201) 321-5146; fax (201) 321-0334.

or

Mary E. Kaufold, Materials Research Society, 9800 McKnight Road, Pittsburgh, PA 15237; telephone (412) 367-3003; $\operatorname{tax}(412) 367-4373$. 